AD D $202 \quad 398$

\title{
MARTENSITIC TRANSFORMATIONS IN IRON ALLOYS
}

\author{
FINAL REPORT
}

PROFESSOR C. MARVIN WAYMAN

OCTOBER 1, 1989 TO SEPTEMBER 30, 1991

\section{U.S. ARMY RESEARCH OFFICE}

$$
\begin{gathered}
\text { DAAL03-89-K-0182 } \\
\text { P-26617-MS }
\end{gathered}
$$

UNIVERSITY OF ILLINOIS AT URBANA-CHAMPAIGN DEPARTMENT OF MATERIALS SCIENCE \& ENGINEERING 1304 WEST GREEN STREET URBANA, IL 61801 


\section{REPORT DOCUMENTATION PAGE}

Public reporting burden for this colfection of information is estumated to average 1 hour per response, includlng the time for reviewing instructions, searching existing data sources, gathering and maintaining the data needed, and completing and reviewing the collection of tintormation. Send comments regarding this burden estimate or any other aspect of this Davis Highway, Suite 1204. Arlington, VA 22202 4302 , and to the Office of Management and Budget, Paperwork Reduction Project (0704-0188), Washington, DC 20503.

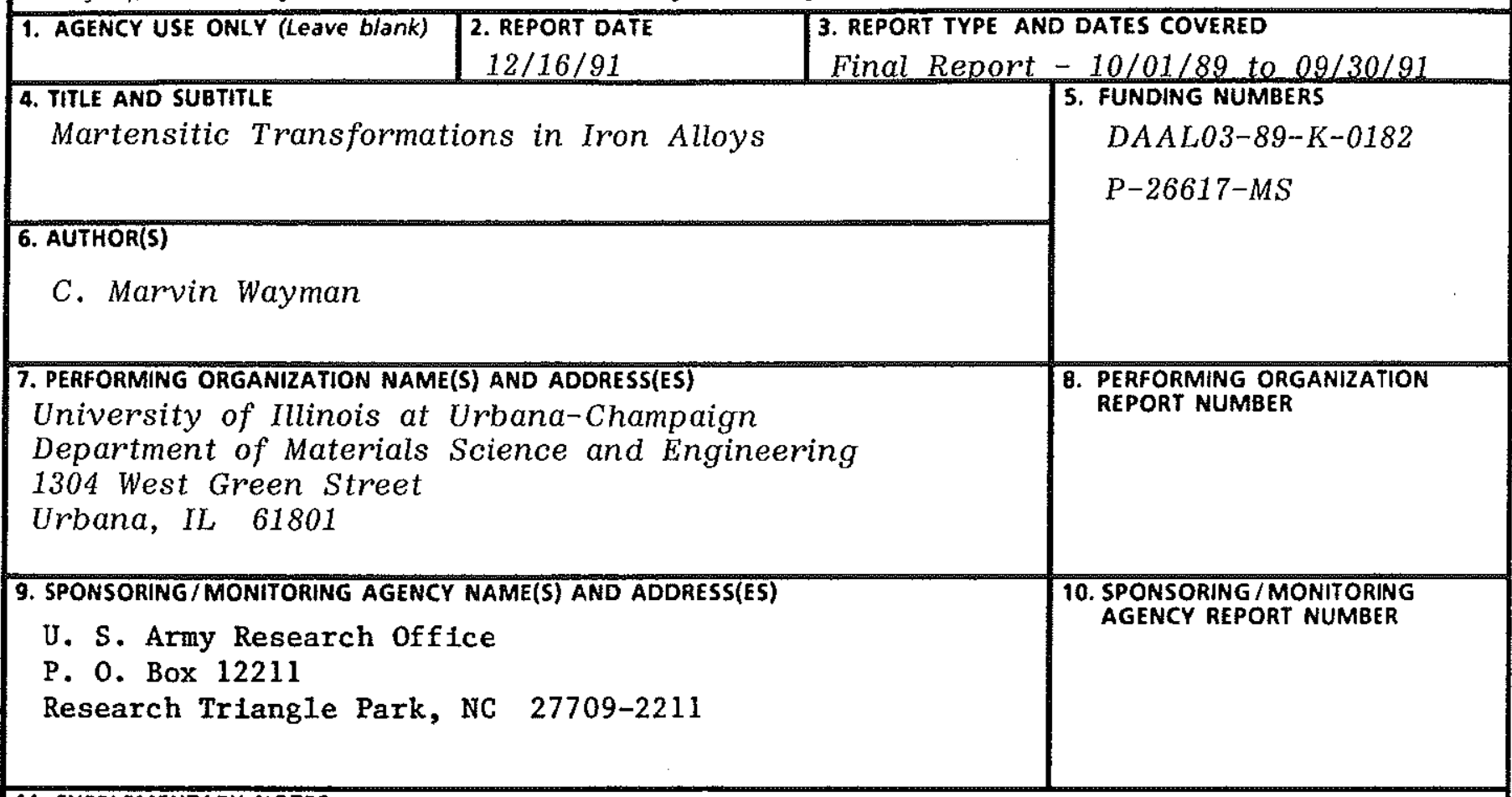

\section{SUPPLEMENTARY NOTES}

The view, opinions and/or findings contained in this report are those of the author(s) and should not be construed as an official Department of the Army position, policy, or decision, unless so designated by other documentation. 12a. DISTRIBUTION/AVAILABILITY STATEMENT 12b. DISTRIBUTION CODE

Approved for public release; distribution unlimited.

\section{ABSTRACT (Maximum 200 words)}

See Attached

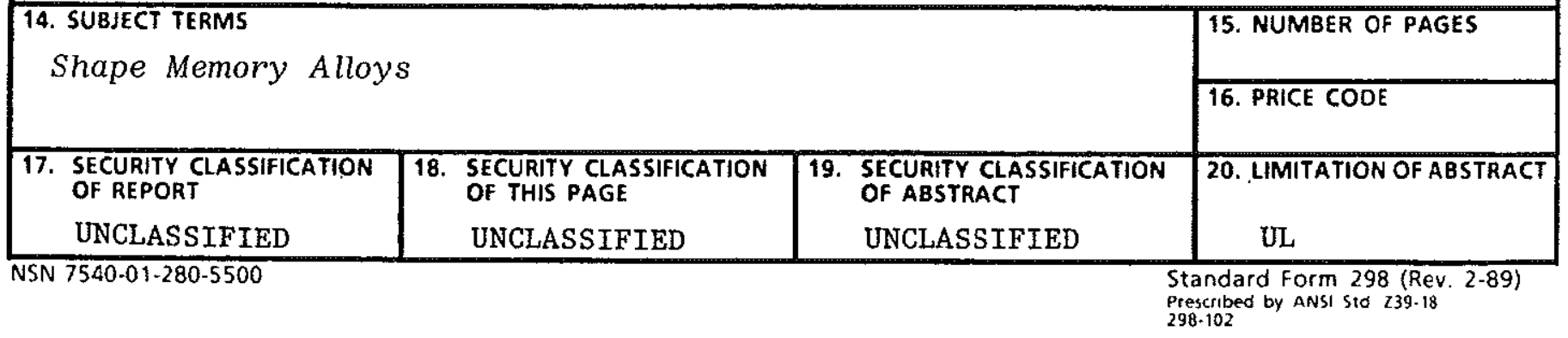


The last phase of this work has been devoted to a study of shape memory ferrous alloys in the nominal Fe-Mn-Si system. Encouraging results were obtained and are summarized below. The work will be published as a series of three papers in Metallurgical transactions. A new (or renewal) proposal is being considered.

As part of a study on newly developed Fe-based shape memory alloys associated with FCC-HCP martensitic transformation, the shape memory behavior is reported and various physical factors influencing it discussed, based on experimental results from dilatometry and bending tests. The alloys studied exhibit a good SME without special training. The SME is significantly improved by prestraining at low temperatures. A higher net reversible strain is made available by over-prestraining, although the fully reversible prestrain usually does not exceed $2 \%$. Superelasticity, the two-way shape memory and a softening effect of the matrix at low temperatures were considered.

Based on present experimental observations and related work, theoretical aspects of the self-accommodation, and shape memory mechanism of e-martensite were considered in comparison with the well-known and widely studied Cu-based shape memory alloys. It. followed that the $\mathrm{g} \vDash E e$ martensitic transformation and its related shape memory behavior share some similarities in selfaccommodation of the transformation and variant reorientation upon deformation. Therefore, the basic processes involved in the shape memory behavior of e-martensite can be similarly generalized in terms of the model established for the Cu-based SMAs, although some details are significantly different. 
As another part of the study on Fe-based shape memory alloys associated with FCC-HCP martensitic transformations, microstructural mechanisms were investigated in relation to the shape memory behavior for different experimental conditions. The shape memory behavior of several typical alloys is interpreted well in terms of the thermodynamic and mechanical aspects of the $\mathrm{e}$ martensitic transformation in competition with various irreversible deformation modes. For the polycrystalline alloys, favorable conditions for a perfect SME can be achieved by properly controlling various physical factors, such as the stacking fault energy, strength of the matrix, $M_{S}$ and $T_{N}$ temperatures and c/a ratio of the e phase. The potential competence of the present alloys for industrial and military applications was considered in the light of our newly proposed intersecting-shear mechanism for a fairly high recovery strain rate. 


\section{Publications}

J. H. Yang and C. M. Wayman, "Development of Fe-Based Shape Memory Alloys Associated with FCC-HCP Martensitic Transformations. I. Shape Memory Behavior," Metallurgical Transactions, in press.

J. H. Yang and C. M. Wayman, "Development of Fe-Based Shape Memory Alloys Associated with FCC-HCP Martensitic Transformations. Il. Transformation Characteristics," Metallurgical Transactions, in press.

J. H. Yang and C. M. Wayman, "Development of Fe-Based Shape Memory Alloys Associated with FCC-HCP Martensitic Transformations. III. Microstructural Interpretation," Metallurgical Transactions, in press.

J. H. Yang and C. M. Wayman, "Self Accomodation and Shape Memory Mechanism of eMartensite. I. Experimental Observations," Materials Characterization, in press.

J. H. Yang and C. M. Wayman, "Self Accomodation and Shape Memory Mechanism of eMartensite. II. Theoretical Considerations," Materials Characterization, in press.

J. H. Yang and C. M. Wayman, "On Secondary Variants formed at Intersections of e-Martensite Variants," Acta Metallurgica, in press.

J. H. Yang and C. M. Wayman, "Intersecting Shear Mechanisms for the Formation of Secondary e-Martensite Variants," Acta Metallurgica, in press.

\section{Personnel:}

S. J. Kim and J. H. Yang 